\title{
土地利用变化对区域碳汇的影响综述
}

陈媛

广东省地图院

DOI:10.32629/gmsm.v3i3.727

[摘 要] 加剧全球变暖的主要原因是二氧化碳在大气中的浓度上升。减少大气中二氧化碳的浓度,除了碳减排,还有增加碳汇。陆地碳汇动力 主要来源于植被, 不同的植被类型碳汇差异较大, 而土地利用变化影响不同植被类型构成, 从而影响区域碳汇能力。国内外已经有众多学者对土 地利用变化对区域碳汇的影响进行总结,本篇文章在此基础上围绕不同植被类型对陆地生态系统的碳循环问题展开,对全球及区域范围内土地 利用变化对林地、草地以及耕地三种陆地碳汇进行综合叙述。过度农垦及建设用地扩张、森林面积缩减并大部分向草地和耕地转化, 导致碳汇 量减少,在具体的数据分析中,温带地区土地利用变化带来的碳汇影响要低于地带地区。

[关键词] 土地利用变化; 生态系统; 碳汇; 影响

\section{1 土地利用变化对区域碳汇的影响总述}

随着人类活动扩张, 过度农垦及建设用地扩张、森林面积缩减等土地 覆盖与土地利用变化, 对化石燃料过度依赖使用, 使大气中温室气体浓度 不断上升。当大气中温室气体浓度不断增加, 导致地球大气系统吸收能量 和发射能量之间不平衡, 能量不断在地球大气中积累, 导致全球气温以非 正常速率上升, 从而造成了全球变暖。碳汇一般指植被从大气中吸收并固 定二氧化碳的机制和过程。陆地碳汇动力主要来源于植被, 植被碳汇在调 节全球碳平衡, 减少大气中二氧化碳的浓度有着不可代替的作用 ${ }^{[1]}$ 。

一般而言, 人类对于土地最大的影响就是开层活动, 开剭活动能够在 很大程度上对陆地生态系统的碳储存能力造成影响, 最明显的就是草地转 变为农田的过程会使得土壤中的碳会大量流失。而草场或是森林转化为农 田这一过程中, 又会使得植被和土壤在碳储量方面是呈现出减少的趋势, 最直接的后果就是生态系统在碳储量方面持续降低。除此之外, 随着社会 经济的快速发展, 城市化进程不断推进, 许多农田已经转变为了建设用地, 陆地碳汇逐步减少。1996年我国方精云 ${ }^{[11]}$ 等利用森林面积以及森林蓄积量 粗略估算我国森林生物量以及生产力。虽然模型计算较为粗糙, 精度较低, 只能作为估算我国碳汇潜力。2007年, 方精云 ${ }^{[12]}$ 等对我国1981 2000 年陆地 森林碳汇进行估算, 同样使用生物量法和蓄积量法, 得出该区域的生物量。 方认为现我国森林面积增加以及森林成长加速, 碳汇量增加。 ${ }^{[5]}$ 接下来将 详细叙述土地利用变化对森林生态系统的影响、土地利用变化对草地生态 系统的影响以及土地利用变化对农业生态系统的影响 ${ }^{[2][3]}$ 。

1. 1 土地利用变化对森林生态系统的影响

碳汇, 主要有森林碳汇、草地碳汇、耕地碳汇、土壤碳汇和海洋碳汇。 由于森林自身碳库约占全球植被碳库的 $86 \%$ 以上, 同时还维持着全球约 $73 \%$ 土壤碳库 ${ }^{[6]}[7]$ 。而且, 森林生态系统与其它陆地生态系统相比具有较高的生 产力。森林生态系统每年固定的碳约占整个陆地生态系统的 $66.7 \%$ 。因此 森林生态系统在调节全球碳平衡、减缓大气中 $\mathrm{CO}_{2}$ 等温室气体浓度上升以

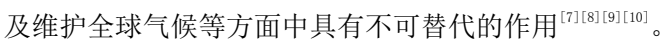

不仅如此, 由于森林生态系统会发生变化, 整个陆地会伴随着这种变 化会向大气中释放一部分碳, 其数据大致为 $(0.9+0.4) \mathrm{PgC}$ 。从总的方面 来说, 土地利用变化对于森林生态系统最大的影响是表现在森林面积缩减 或转化为其他用地, ${ }^{\left[{ }^{[5]}\right.}$ 包括森林转化为农田或者是森林转化为草地, 同时 也包括工业用材的加工或者是不适当的管理等等方面, 这些活动都会对森 林生态系统造成影响。尤其是森林转化为农田或者是森林转化为草地, 都 会在很大程度上使得森林上生物量减少, 同时也会使得土壤中碳的含量有 所降低。这个原理是因为森林地上生物量一旦减少, 就会在很大程度上使
土壤中碳的含量降低。再加上覆被类型改变, 会使得土壤的温度发生变化。 这样不仅会使有机碳快速分解, 还会在很大程度上加剧其释放到大气的速 度。究其毁林的原因, 一般情况下是为了增加草场的面积或者耕地的面积, 也有一些原因是对森林进行不适当的管理。据科学数据表明, 在发展中国 家, 有 60 多个国家是通过毁林来实现草场面积和耕地面积的增加的, 有 40 多个国家对森林进行砍伐主要是为了烧炭, 对木材进行使用, 还有 30 多个 国家是因为对森林管理方法不当使得森林退化 ${ }^{[4]}$ 。

\section{2 土地利用变化对草地生态系统的影响}

草地生态系统作为大陆生态系统的重要组成部分, 它的总面积是大陆 总面积的四分之一, 在数值上表现为大于 $3.0 \mathrm{Ghm}$, 在全球范围内, 草地生态 系统在碳储存量方面的数值可以达到 $266.3 \mathrm{PgC}$, 这个数值占据了大陆生态 系统碳储存量的 $13 \%$ 左右。另一方面。对于草地生态系统来说, 草地的碳储 存量有很大一部分。是存在于土壤中的。因此土地利用变化对于草地生态 系统的影响可以看做是土地利用变化对于土壤碳储量的影响。这个影响可 以从两方面来说, 一方面它能够影响进初级的生产力, 从而在很大程度上 对土壤的碳储量进行直接的改变。

另一方面, 温度的变化间接改变土壤的有机碳储量。前文提到, 对于生 态系统影响最大的人类行为就是开层活动。而对于草地生态系统而言, 开 垦活动更多的指的是将草地转化为农田。在这个转化的过程中, 农田碳汇 能力比草地低, 区域呈现碳排放趋势。曾经有外国的科学家对于奥地利阿 尔卑斯山进行了研究, 研究的内容就是土地利用变化对于草地生态系统的 影响 ${ }^{[5]}$, 在这个研究中, 我们可以通过数据看出放牧之后或者是收割之后 草地就能够从碳会转化为碳源。而对于草地进行科学合理的管理, 其最有 效的体现是在生物量方面远远高于那些没有对草地进行科学管理的地方。 因此我们可以认为要想减少土地利用变化对草地生态系统的影响, 我们可 以增加草地覆盖度, 减少放牧, 减少人类活动对于草地生态系统的影响, 同 时对于退化的草地严禁放牧、对它们进行科学合理的施肥。

1.3 土地利用变化对农业生态系统的影响

从生物学的角度而言, 如果农业生产活动过多, 会使得土壤呼吸的强度 增加。森林向农田进行转变的过程中会使得植被的碳储量降低, 土壤的碳储量 也会在很大程度上减少。从原来的耕作方法来看, 比较传统的耕作方式会使得 碳素在土壤中停留的时间过短, 这样将会在很大程度上加剧土壤碳的流失。随 着城市化建设的不断推进, 许多耕地已经转化成了建设用地, 在耕地转化为建 设用地的过程中实际上是碳排放的一个过程, 它能够对植被对土壤造成很重 要且深远的影响。因此要想减少土地利用变化对农业生态系统的影响, 就要对 土地进行科学合理的管制, 使它能够减少碳排放, 同时适应气候的变化。 


\section{测绘工程测量中无人机遥感技术的运用分析}

屠金龙

霍邱县自然资源执法监察大队

DOI:10.32629/gmsm.v3i3.744

[ 摘 要] 本文将对无人机遥感技术的概述及实施效果进行简要的分析阐述,并以此为基础,指出测绘工程测量中无人机遥感技术的运用,以期能 够为业内人士提供理论参考。

[关键词] 测绘工程; 无人机遥感技术; 工程测量

随着科学技术的不断发展与普及, 如今测量工程测量也逐步实现了信 息化、科学化的发展。当今测绘工程测量中, 无人机遥感技术作为运用最 广泛的新型测绘技术, 其将可以有效提高测量工程的测量效果, 进而为后 续工程提供更加精准有效的数据信息。然而, 从实际应用情况来看, 在如今 的测绘工程测量中, 无人机遥感技术的运用仍旧有着诸多优缺点, 确定无 人机遥感技术的实际应用情况, 以期能够促进我国无人机遥感技术在测量 工程测量中的进一步运用。

\section{1 无人机遥感技术的概述}

通常来说, 无人机遥感技术主要有飞行器、无线操控设备, GPS定位系 统、信息采集传感器以及数据处理器五部分组成。现有的无人机遥感技术 不仅有效的采用了我国先进的无人机技术、GPS定位技术以及数据处理系 统等高新技术, 还实现了对多种高新技术的有机结合, 促使无人机遥感技 术运用在测绘工程测量中, 能够有效的发挥出致使的实际效果 ${ }^{[1]}$ 。

在过去的测量工程测量中, 很多测量工作都需要工作人员在飞行器以 及人造卫星的帮助下进行, 其不仅有着人力需求性大, 测量成本高等特点, 实际测量效果还会受到测量区域的天气等因素的影响。相比较之下, 无人 遥感技术的可操作性更强, 工作人员不仅可以通过无线操控设备来实现对 无人机的手动控制, 也可以通过预先设置飞行航线的方式来实现无人机的 自主控制, 并在达到测量区域后, 无人机可以自动获取测量区域的图像、影 像以及其他数据等信息, 完成数据信息采集工作。除此之外, 基于无线通信 技术, 无人机还可以实现与地面操控室的实时数据交互效果, 提高数据信 息的传递效率同时, 还能够及时发现并解决测量中存在的问题, 缩短测绘

总的来说, 土地利用变化对于区域碳源汇的影响还是十分大的, 需要 引起高度的重视, 本篇文章先是对土地利用变化对区域碳源汇的影响进行 了总的叙述, 只有又详细的论述了土地利用变化对森林生态系统、草地生 态系统以及农业生态系统的影响。在此基础上对土地利用变化的影响进行 了总结, 并对其未来发展方向进行了研究和论述, 希望能够引起相关学者 的注意, 在未来加强对各方慢的研究, 不断完善分析方法和系统模型, 使研 究结果更具有显示意义和参考价值。

\section{[参考文献]}

[1]马晓哲,王铮.土地利用变化对区域碳源汇的影响研究进展 [J].生 态学报,2015,35(17):5898-5907.

[2]赵明伟,岳天祥,赵娜, 等.基于HASM的中国森林植被碳储量空间分布 模拟[J].地理学报,2013,68(09):1212-1224.

[3]曹铭昌,乐志芳,雷军成, 等.全球生物多样性评估方法及研究进展 [J].生态与农村环境学报,2013,29(01):8-16.

[4] 陈卓奇,郡全琴,刘纪远,等.基于MODIS的青藏高原植被净初级生产 力研究[J].中国科学:地球科学,2012,42(03):402-410.
周期, 降低测绘成本。因此, 无人机遥感技术在我国测量会工程测量中得到 了广泛运用。

\section{2 在实际测绘工程测量中无人机遥感技术的效果}

2.1 无人机遥感技术的优势

首先, 无人机遥感技术的灵活性更强。相比较传统的载人飞行器测量 方式来说, 无人机遥感技术中所使用的无人机设备体积更小, 其内部所配 置的相关设备也更加精简且符合测绘工程测量的实际需求, 进而促使无人 机遥感技术有着更高的灵活性同时, 还能够有效确保无人机遥感技术在实 际测绘工程测量中的实际运行效果。

其次, 无人机遥感技术中集成了计算机技术和数据处理技术等高新科 技技术, 基于该些技术, 无人遥感技术可以将所获取到的数据信息进行初 步处理, 并通过无线通信技术实施传输给地面控制站, 减少工作人员的数 据处理流程, 提高数据处理效果。除此之外, 由于无人机遥感技术所采用的 无人机设备体积相对较小, 所以其可以进入到载人飞行器所无法进入到的 狭窄空间中进行数据信息采集工作, 也同样可以达成广阔空间的数据信息 采集效果, 其是导致无人遥感技术在如今测绘工程测量中逐步取代传统测 量技术的主要根源所在 ${ }^{[2]}$ 。

再次, 如今无人机遥感技术中还集成了三维仿真模拟技术, 结合无线 通信技术, 所达成的数据信息实时交互效果, 促使地面控制站的工作人员 可以实时接收到更加直观立体的测绘图像。

最后, 无人机遥感技术还集成了分辨率较高的数码转换器和数据处理 器, 相比较传统的测绘工程测量技术来说, 无人机遥感技术所获取到图像 